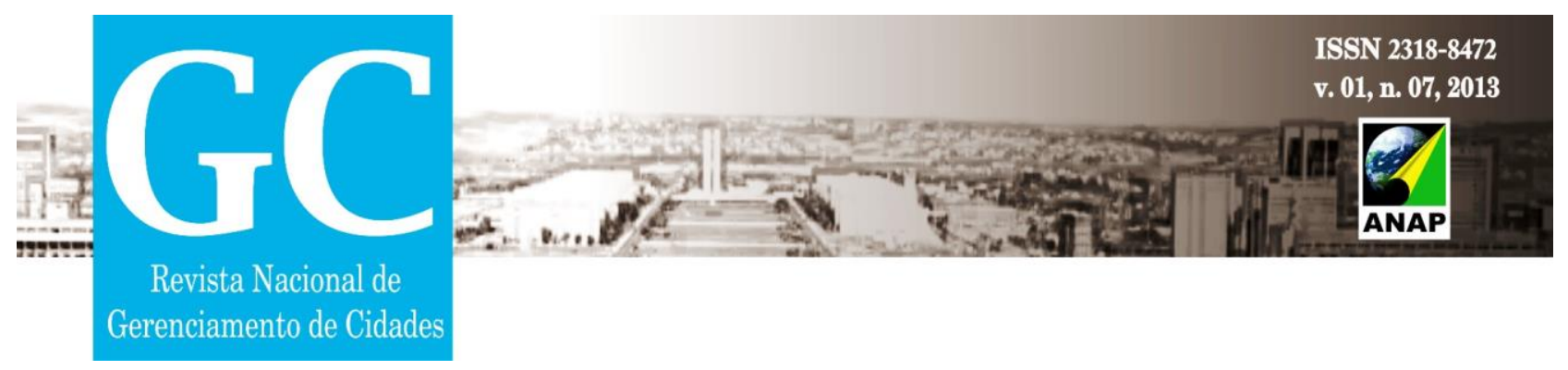

\title{
A MISSÃO DE PESQUISAS FOLCLÓRICAS REALIZADA PELO DEPARTAMENTO DE CULTURA DE SÃO PAULO NA GESTÃO DE MÁRIO DE ANDRADE (1934 A 1938) E SUA CONTRIBUIÇÃO PARA A CULTURA POPULAR BRASILEIRA.
}

\section{Patricia Cecilia Gonsales ${ }^{1}$}

Resumo: $O$ artigo trata da importante contribuição que o Departamento de Cultura da cidade de São Paulo na gestão de Mário de Andrade (1934 a 1938) trouxe para a cultura brasileira. Em 1938, o departamento organizou a Missão Folclórica liderada por Luís Saia com o objetivo de retratar manifestações folclóricas no interior do norte e nordeste brasileiro. O material recolhido pela Missão foi além dos registros de músicas, danças, contos, festas e cerimônias religiosas populares. Os membros da expedição retrataram também dados relativos à cidade, instituições e à arquitetura que traduziam o cotidiano da vida nas comunidades, tornando o material tão rico que o estudo aprofundado do acervo só foi possível a partir de 1990. Atualmente o material foi reconhecido pelo Instituto de Patrimônio Histórico Artístico Nacional (IPHAN). Para a pesquisa foram utilizadas fontes documentais primárias e fontes bibliográficas secundárias. A Missão Folclórica foi um dos vários projetos desenvolvidos pelo Departamento de Cultura na Gestão de Mário de Andrade, ocorrido em uma época em que o debate sobre a identidade brasileira estava em evidência e o Brasil procurava tornar-se Nação.

Palavras-Chave: Folclore. Preservação. Patrimônio.

\footnotetext{
${ }^{1}$ pcgonsales@uol.com.br
} 


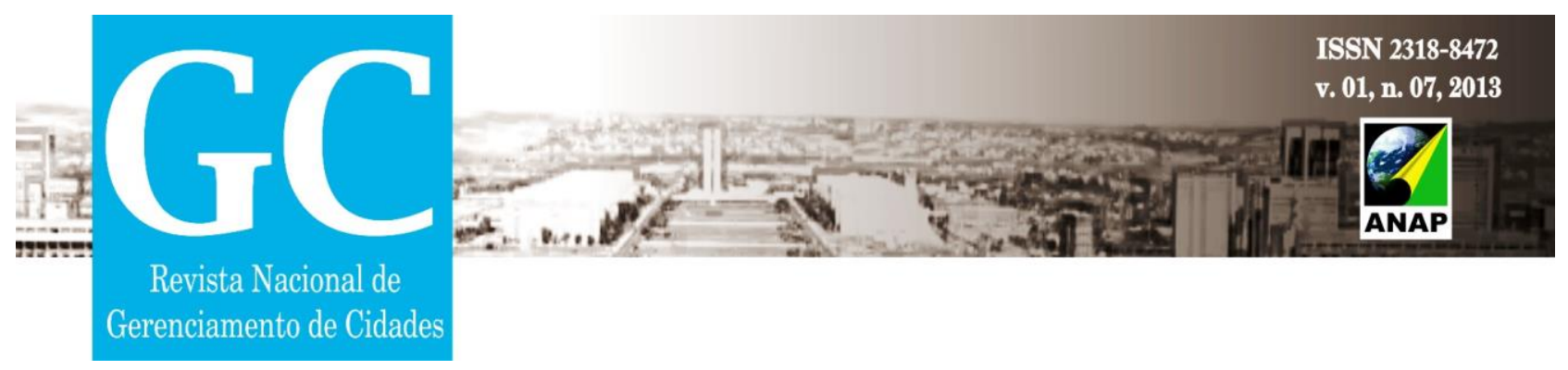

\section{AS DISCUSSÕES SOBRE IDENTIDADE CULTURAL BRASILEIRA: PRECEDENTES DO DEPARTAMENTO DE CULTURA.}

Pois foi nessa sala, em torno da fria mesa de granito, que um de nós - quem poderá saber qual de nós? - falou em perpetuação daquela roda numa organização brasileira de estudo de coisas brasileiras e de sonhos brasileiros. ${ }^{2}$

Desde o início da década de trinta, o debate sobre identidade brasileira estava em voga no país. Para isso, era preciso estudar a cultura de todas as regiões, ressaltar aquilo que parecia de mais genuíno. A sociedade se contagiou com mensagem nacionalista trazida pelo movimento modernista iniciado na década anterior e procurava agora conhecer-se. Um país que abrigava tantos povos provenientes de tantos países diferentes revelava a urgência em se definir a identidade do povo brasileiro. Essa identidade seria a afirmação do Brasil como Nação.

O assunto não era objeto de discussões apenas dos intelectuais, mas também na política. Um personagem importante neste período foi Gustavo Capanema, nomeado por Getúlio Vargas para ocupar a pasta do Ministério da Educação e Saúde. Adriana Lopez e Carlos Guilherme Mota analisam o momento:

Capanema logrou reunir uma plêiade de alto nível, articulando para tal fim um sistema cultura que envolvia os campos da educação, da música, do patrimônio histórico e artístico, da arquitetura, sob coordenação de seu chefe de gabinete, o meticuloso [Carlos] Drummond [de Andrade].3

Em 1934 Fábio Prado assumiu a prefeitura de São Paulo e seguindo as tendências do governo federal, convidou Paulo Duarte para apresentar um projeto para o Departamento de Cultura do município. O projeto para a Secretaria de Cultura era um

\footnotetext{
${ }^{2}$ DUARTE, Paulo. Mário de Andrade por ele mesmo. Ed. HUCITEC, Prefeitura Municipal de São Paulo, São Paulo, 1985, p. 51.

${ }^{3}$ LOPEZ, Adriana; MOTA, Carlos Guilherme. História do Brasil. Uma Interpretação. SENAC São Paulo, Ed.3 2012 , p. 682.
} 


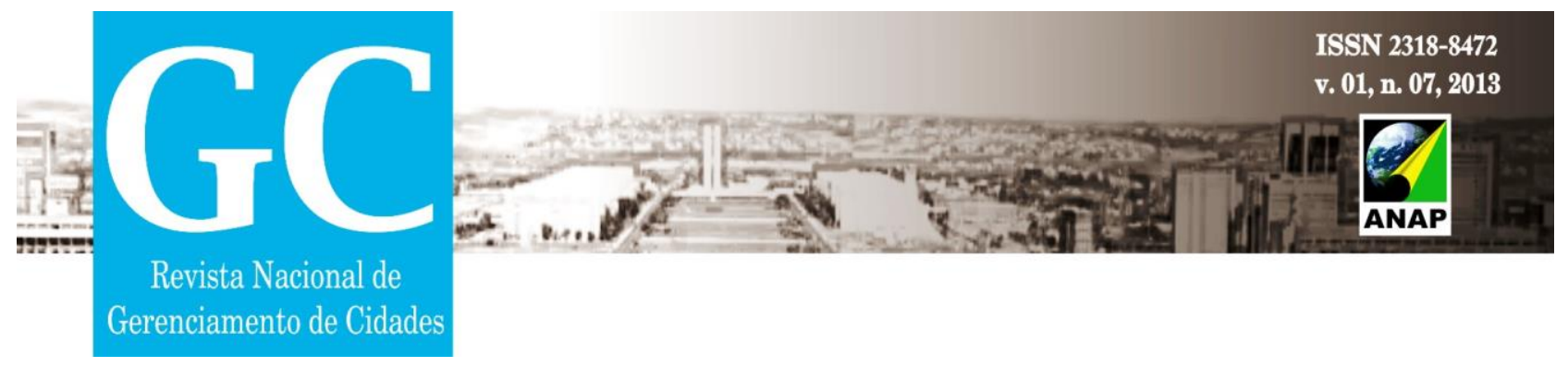

sonho antigo do grupo formado por Paulo Duarte, Mário de Andrade, Antônio de Alcântara Machado, Tácito Almeida, Sérgio Milliet, Antonio Couto de Barros, Henrique Rocha de Lima, Randolfo Homem de Melo, Rubens Borba de Moraes e Nino Gallo; amigos que se reuniam quase que diariamente no apartamento de Paulo Duarte, na Avenida São João, para discutirem cultura, identidade brasileira e preservação do patrimônio histórico brasileiro.

Com a possibilidade concreta de tornar real tudo aquilo que idealizavam nas reuniões entre amigos, Paulo Duarte, Mário de Andrade e alguns intelectuais da época estruturaram o projeto que apresentariam a Fábio Prado que, analisando o conteúdo, aprovou de imediato. Mário de Andrade foi convidado para ser o diretor do departamento tomando posse do cargo no início de 1935.

\section{AS NOVAS PROPOSTAS E A POLÊMICA TRAZIDAS PELO DEPARTAMENTO DE CULTURA E SUAS MISSÕES DE PESQUISA FOLCLÓRICAS.}

Deus Me Livre M’Ermão! Sou O Homem Mais Feliz Do Mundo. E O Meu Sossego? Não Quero Abandona Ele Não! ${ }^{4}$

O Departamento de Cultura do Município de São Paulo na gestão de Mário de Andrade estava dividido em cinco divisões que se subdividiam conforme suas atribuições. As divisões revelam claramente a preocupação em criar acessos à arte e cultura para as camadas menos abastardas da sociedade. Dentre as divisões do departamento, havia a divisão de Bibliotecas; de Educação e Recreios; de Documentação Histórica, Social e Estatísticas; de Turismo e Divertimentos Públicos e a Divisão de Expansão Cultural, que tinha a função de favorecer movimentos culturais e educacionais. Estava dividida em duas

\footnotetext{
${ }^{4}$ Frase atribuída a Mário de Andrade quando recebeu o convite para dirigir o Departamento de Cultura de São Paulo de 1934 a 1938. In: DUARTE, Paulo, op. cit., p. 52
} 


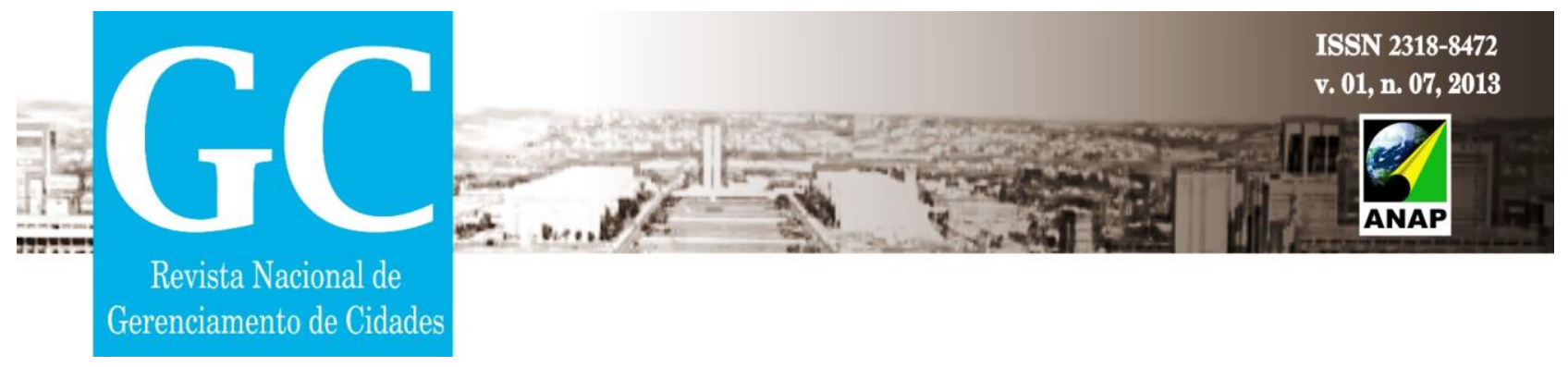

subseções: a de teatros, salas de cinemas e salas de concerto e a subdivisão de radioescola, a qual estava anexa a Discoteca Municipal.

Algumas das incumbências previstas no Regulamento do Departamento de Cultura não chegaram a ser criadas. A verdade é que essa estrutura previa a criação de muitas instituições, algumas delas deveriam ser criadas em âmbito nacional, como é o caso do SPHAN (secretaria encarregada da preservação dos monumentos históricos brasileiros) criado por Rodrigo Melo Franco seguindo os moldes propostos pelo projeto de Mário de Andrade entre os anos de 1937 e 1938 e dirigido pelo arquiteto e urbanista Lucio Costa. Paulo Duarte, um dos mentores do Departamento de Cultura revela o ritmo acelerado de trabalho do grupo e os planos para o departamento:

E o trabalho continuava dia e noite. Levantamentos demográficos feitos cientificamente; restauração de documentos quase perdidos; museu da palavra; pesquisas folclóricas; congresso da língua nacional cantada; e coro madregalgista já organizado; setor de iconografia; um verdadeiro tesouro de publicações, um grande prédio para a biblioteca, participação na Exposição de Paris em 1937; preparativos para o grande Instituto Brasileiro de Cultura, que seria a etapa final e natural do Departamento de Cultura; o diabo enfim. Paris fazia um departamento igual. Praga também. A cada notícia assim, era um daqueles sorrisos de crânio aberto traindo o homem (Mário de Andrade) completamente feliz. ${ }^{5}$

Uma parte importante do projeto do Departamento de Cultura foram as pesquisas etnográficas e folclóricas, que segundo Paulo Duarte pretendia servir de base para a criação do Instituto Brasileiro de Cultura. Inicialmente, essa incumbência era da Divisão de Documentação Histórica e Social sob a direção de Sérgio Milliet, mas Mário de Andrade se envolveu pessoalmente no projeto que ficou sob a responsabilidade da Divisão de Expansão Cultural. A Missão de pesquisa etnográfica foi liderada por Levi Strauss em 1937. Já a Missão de Pesquisas Folclóricas foi liderada por Luis Saia em 1938. Carlos Augusto Calil comenta:

\footnotetext{
${ }^{5}$. Ibid., p. 53-54.
} 


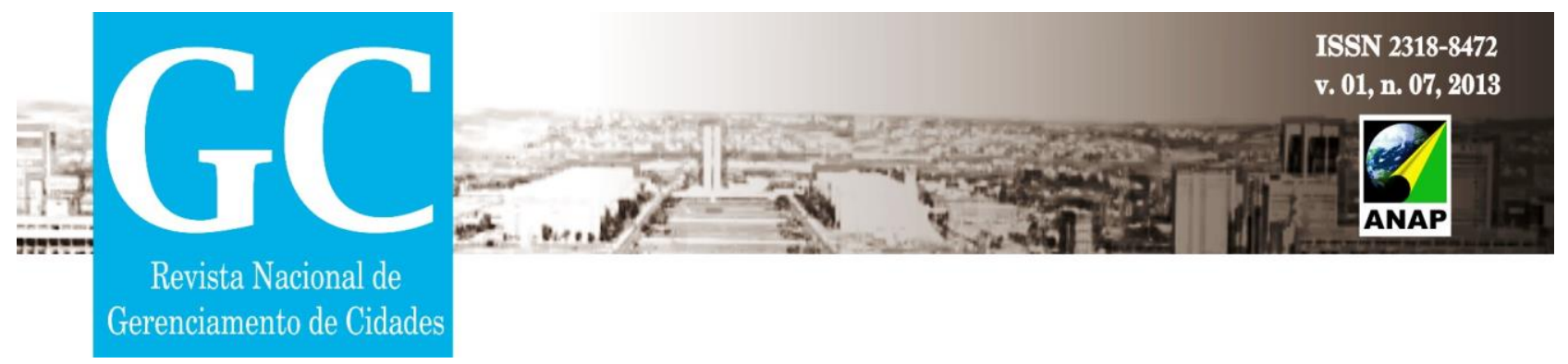

Em 1938 partiram de São Paulo em direção ao Norte-Nordeste quatro pesquisadores e técnicos com a missão de anotar, desenhar, fotografar, filmar, gravar manifestações da nossa cultura profunda e recalcada, além de recolher objetos, instrumentos e artefatos. No espírito século 19 das grandes expedições científicas, embrenhadas no interior remoto do País, o grupo carregava uma tralha imensa: os recém-criados equipamentos de gravação de imagem e som, de difícil manuseio e inadaptados à mobilidade. ${ }^{6}$

Mário de Andrade e a equipe do Departamento de Cultura realizavam pesquisas sobre o Folclore, etnologia (em especial a indianista) e patrimônio histórico do Estado de São Paulo juntamente com professores da Universidade São Paulo e Escola Livre de Sociologia e Política ambas contavam com um quadro docente de europeus, no caso da USP e predominantemente de americanos no caso da Escola Livre de Sociologia que vieram ao Brasil interessados em realizar pesquisas no país. Em parceria com a Sociedade de Etnologia e Folclore de São Paulo pesquisas realizadas sobre o folclore paulista resultaram em um convite para participar do Congresso Internacional de Folclore em 1937 realizado na cidade de Paris onde Nicanor Miranda, chefe da Divisão de Educação e Recreios e presidente da Sociedade de Etnologia e Folclore, apresentou o estudo.

O estudo apresentado em Paris rendeu elogios, mas o Congresso foi importante principalmente por tratar de questões que norteariam o projeto da missão de pesquisas folclórica liderada por Luís Saia que ocorreria no ano seguinte, em 1938. O objetivo do Congresso $^{7}$ era o de incentivar pesquisas antropológicas e sociais sobre folclore em vários países e o assunto era tratado em dois eixos temáticos distintos: $O$ primeiro estava relacionado à descrição da manifestação folclórica. Compunham temas para discussão o estudo das estruturas sociais, tradições e leituras orais e a metodologia folclórica. O outro eixo temático era o folclore aplicado à vida social; os assuntos abordados eram relacionados à arte popular; mocidade e folclore; construções modernas e registro de músicas, danças, contos, festas e cerimônias populares.

\footnotetext{
${ }^{66}$ CALIL, Carlos Augusto. Mário da Cultura Andrade. In: CERQUEIRA, Vera Lucia Cardim de; Org. Cadernetas de Campo. Ed. Associação Amigos do Centro Cultural São Paulo, 2010, p. 3.

${ }^{7}$ MIRANDA, Nicanor. O Congresso Internacional de Folclore. Revista do Arquivo Municipal de São Paulo, v. XLII, p. 79 96, dez. 1937.
} 


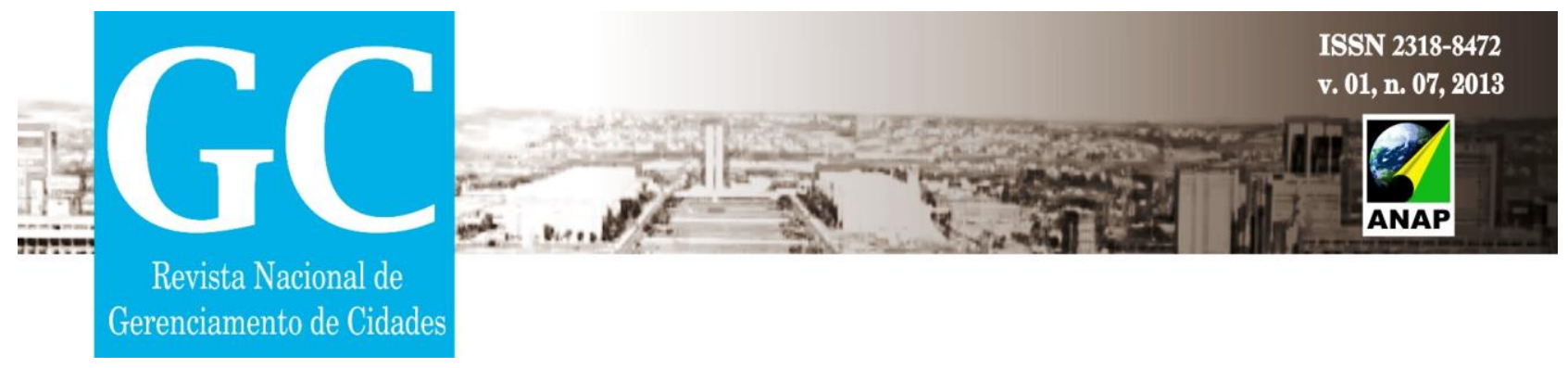

Algumas das principais resoluções do Congresso $^{8}$ foram no sentido de preservar manifestações culturais folclóricas. No evento ficou definido que cada país participante deveria criar uma Instituição oficial nacional dedicada à estudos do Folclore nacional. Deveriam também ser criadas cadeiras em universidades públicas que se dedicassem ao estudo do tema que também deveria fazer parte do programa de estabelecimentos de ensino de base.

A Missão de pesquisa Folclórica idealizada por Mário de Andrade tinha o propósito de registrar elementos culturais ameaçados de desaparecerem em função da chegada da indústria cultural estrangeira no país. Mário de Andrade tinha urgência em editar uma enciclopédia folclórica nacional ilustrada como forma de preservar a cultura interiorana brasileira.

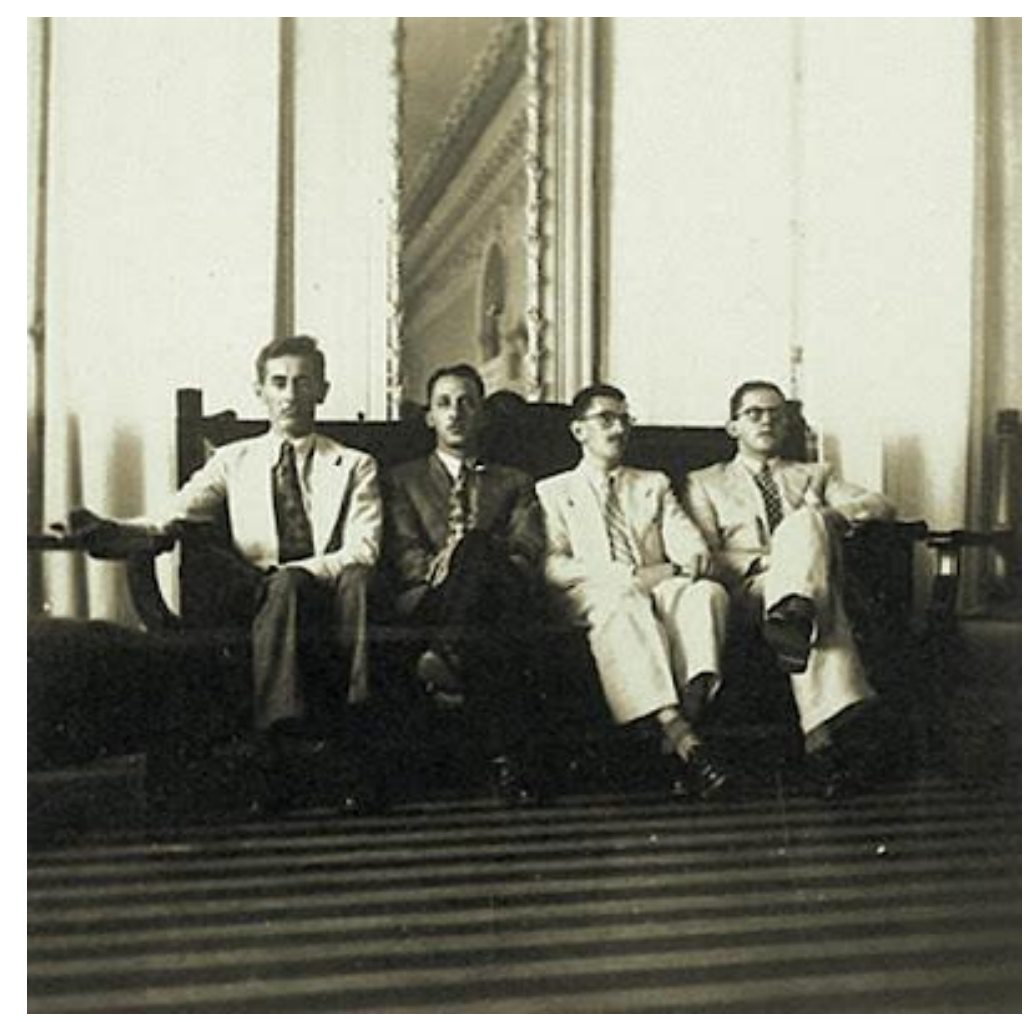

Figura 1: Os membros da Missão de Pesquisas Folclóricas. Martin Brauwieser, Luís Saia, Benedito Pacheco e Antonio Ladeira. Foto tirada em março de 1938 em Recife (PE) - Autoria da imagem desconhecida.

\footnotetext{
${ }^{8}$ In bid p.81.
} 


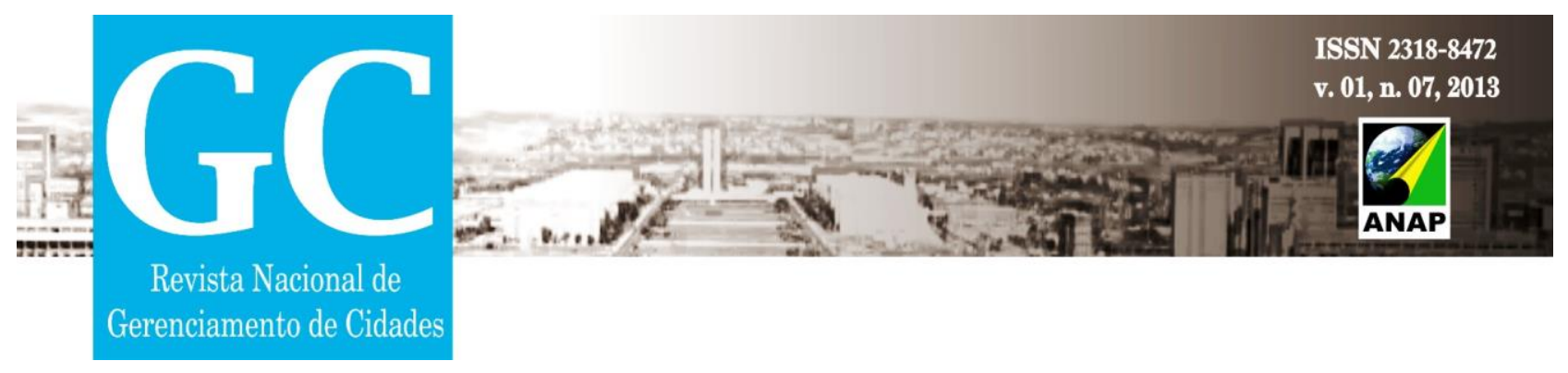

A Missão liderada por Luis Saia contava com Martin Braunwieser, técnico musical, Benedicto Pacheco, técnico de som e Antonio Ladeira, ajudante geral; a viagem de pesquisa teve a duração de seis meses. Todos estavam instruídos a anotarem informações colhidas durante os levantamentos de campo e entrevistas. Tudo isso fazia parte da sistematização na coleta de dados, conforme a metodologia apresentada no Congresso de Paris. Para as anotações feitas ao longo da Missão, os pesquisadores usaram mais de vinte cadernetas e um total de 3.500 páginas escritas ${ }^{9}$. A organização das cadernetas usadas durante a Missão de pesquisas Folclóricas não foi uma tarefa fácil, pois não foi possível ordená-las por temática, cronologia ou pelas localidades visitadas. Flávia Camargo Toni descreve:

Elas (as cadernetas) registram os dados dos colaboradores que participaram das danças e cantorias, descreveram objetos coletados e numerados com etiquetas de controle, assim como descreveram esquemas de alguns bailados, fixaram os detalhes que pareciam imprescindíveis para a recuperação dos dados, como se fosse possível depois, reconstruir o ambiente da atividade de pesquisa e registro. ${ }^{10}$

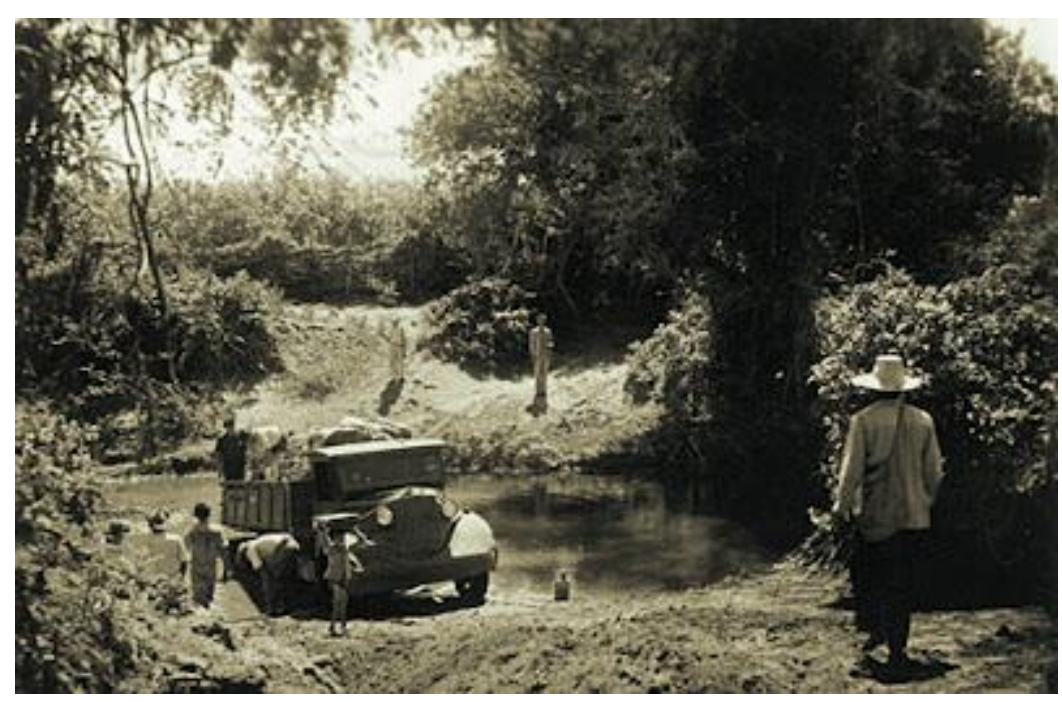

Figura 2: Caminhão que levava os membros da Missão de Pesquisas Folclóricas (1938). Autoria da imagem desconhecida.

\footnotetext{
${ }^{9}$ SAIA NETO, José. Chegamos Bem. In: CERQUEIRA, Vera Lucia Cardim de; Org. Cadernetas de Campo. Ed. Associação Amigos do Centro Cultural São Paulo, 2010, p. 74.

${ }^{10}$ TONI, Flávia Camargo. As cadernetas da missão de pesquisa folclórica. In: CERQUEIRA, Vera Lucia Cardim de; Org. Cadernetas de Campo. Ed. Associação Amigos do Centro Cultural São Paulo, 2010, p. 27.
} 


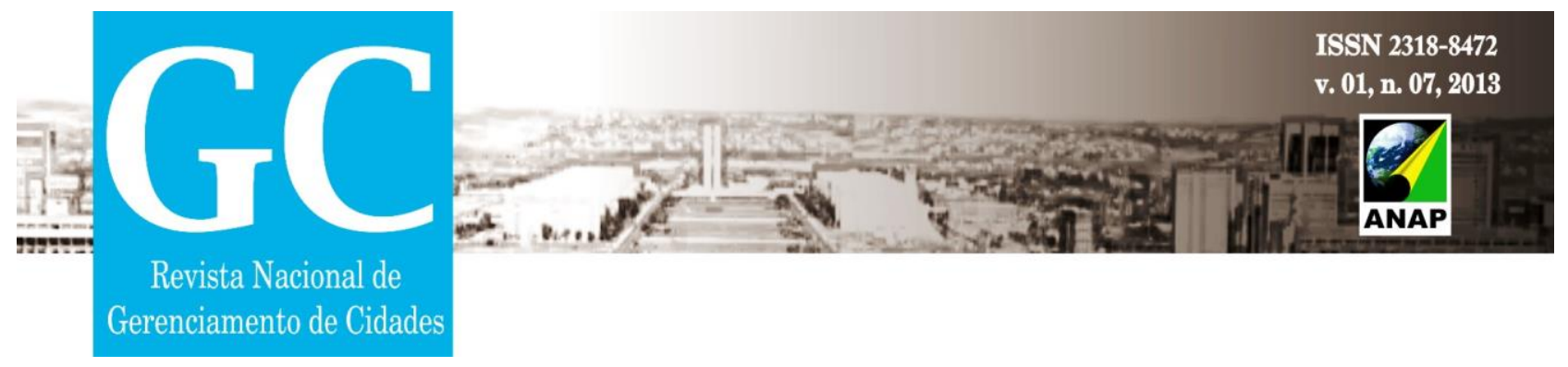

O objetivo da Missão era registrar cantigas, danças e festas tradicionais do norte e nordeste do Brasil e o material colhido foi farto e de muito boa qualidade. No entanto, Luis Saia e sua equipe foram além dos propósitos iniciais e colheram também dados relativos à cidade, instituições e à arquitetura que traduziam o cotidiano da vida nas comunidades, relatando técnicas de trabalho e dados relativos à infraestrutura desses povoados. $O$ acréscimo das informações colhidas conforme os interesses pessoais de Luis Saia ampliaram o campo de observações e tornaram o material da pesquisa mais rico do que se pretendia inicialmente.

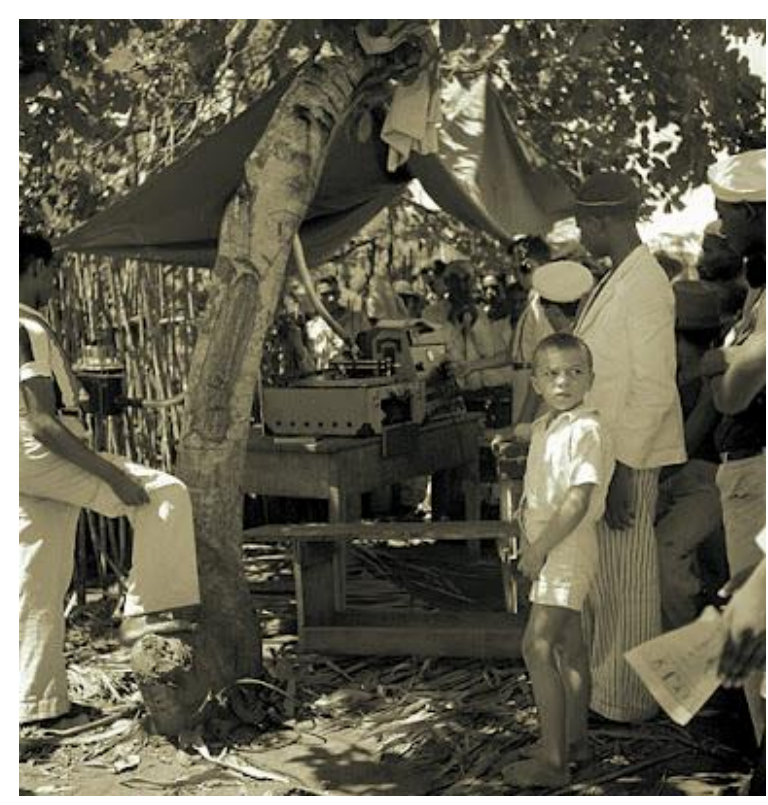

Figura 3: Cena no registro de material sonoro na cidade de Torrelândia, João Pessoa (PB). Autoria da imagem desconhecida. 

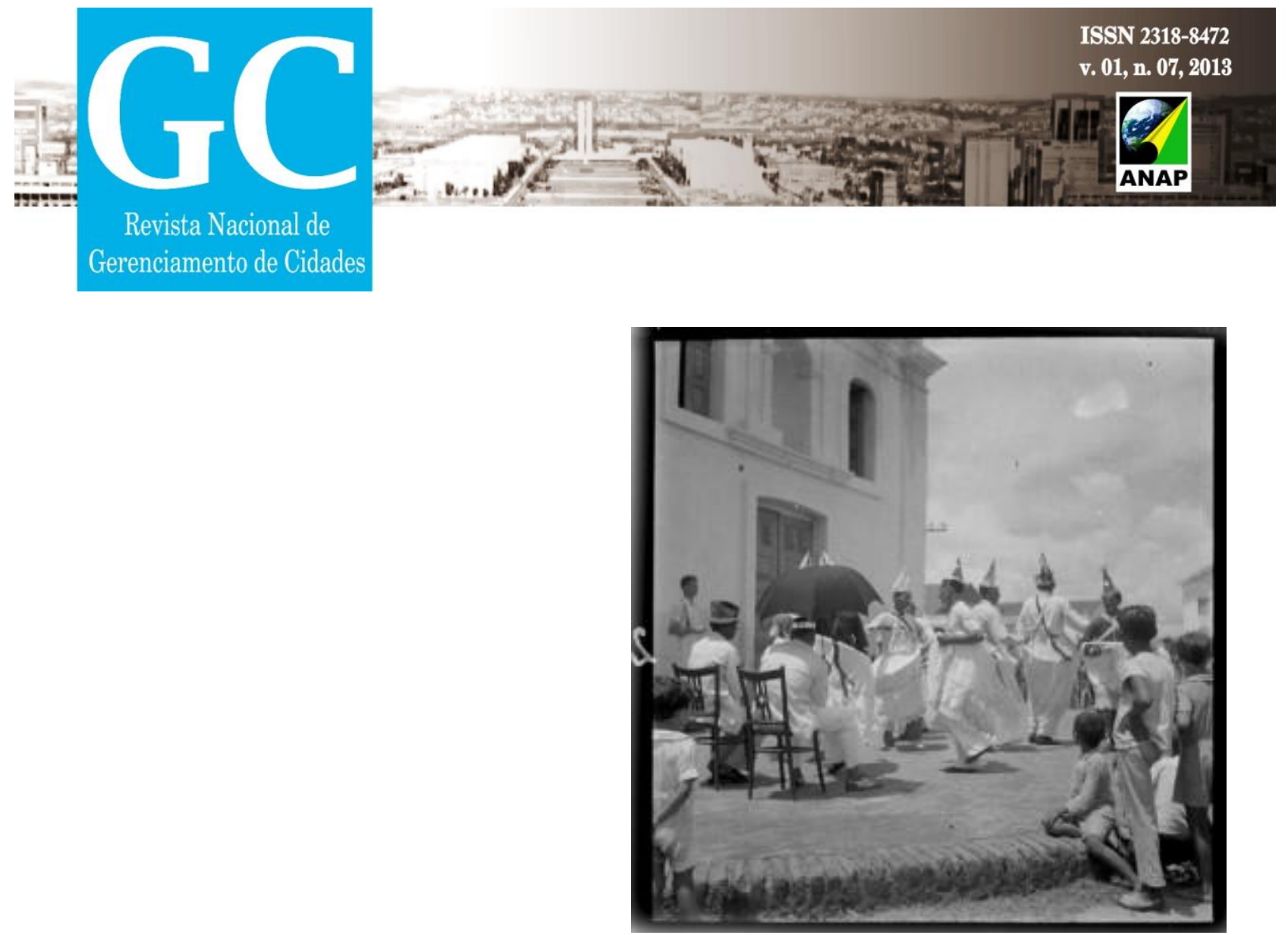

Figura 4: Reis de Congo em Pombal, Paraíba (1938).

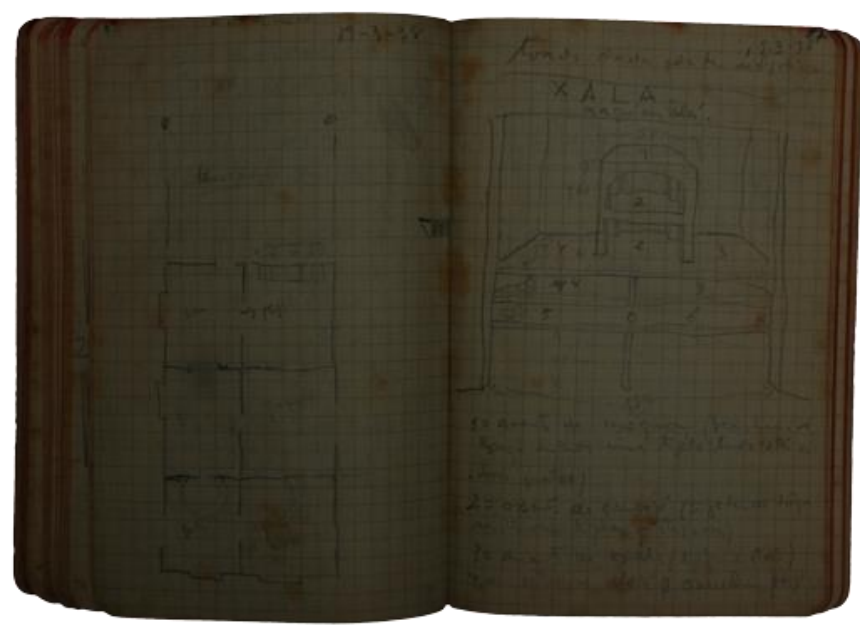

Figura 5: Uma das páginas da caderneta 1B.

No entanto, assim como uma boa parte dos projetos do Departamento de Cultura, o projeto da enciclopédia folclórica nacional ilustrada era caro e foi alvo de críticas duras feitas principalmente no cenário político. Fábio Prado, prefeito de São Paulo na época deixou o cargo que seria assumido por Prestes Maia. O Departamento de Cultura e seus grandes projetos não estavam nos planos do novo prefeito. As acusações foram várias, 


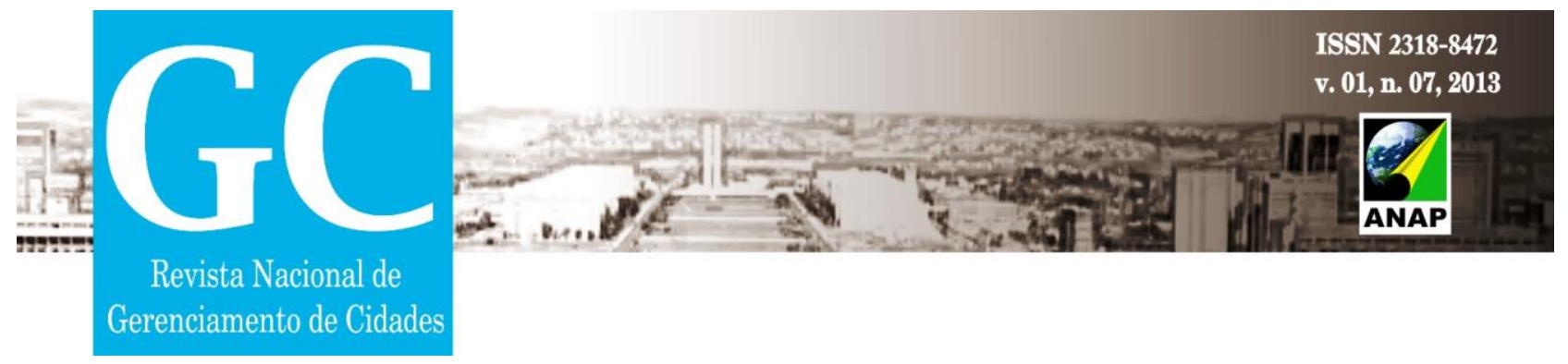

relacionadas a abuso de dinheiro público, negociatas; e Mário de Andrade foi demitido e acusado de perdulário, antes que os pesquisadores da Missão retornassem à São Paulo. Após a demissão de Mário de Andrade o Departamento de Cultura foi seriamente prejudicado, a Divisão de Expansão Cultural foi inteiramente arquivada, as verbas liberadas por Fábio Prado para os projetos do departamento foram todas desviadas para outras áreas da prefeitura.

Nos anos seguintes, Oneyda Alvarenga $^{11}$, Camargo Guarnieri e outros pesquisadores chegaram a estudar o material trazido pelos integrantes da Missão Folclórica, mas a tecnologia avançada utilizada da época das pesquisas havia se tornado obsoleta e a extensão do material era tão grande que a exploração de tudo o que estava registrado ficou impraticável com os recursos disponíveis até então. Oneyda Alvarenga recolheu o material anexando-o ao acervo da Discoteca Pública paulistana.

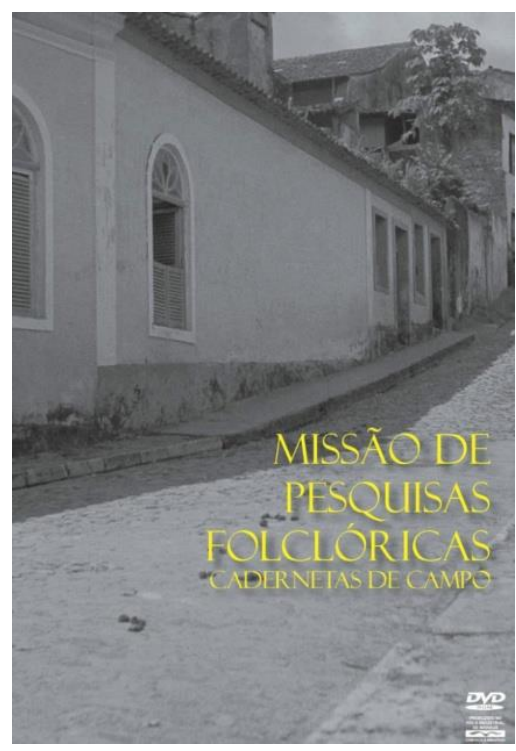

Figura 5: Material composto por 1 livro e 1 DVD sobre o conteúdo das cadernetas de campo de Luís Saia e sua equipe.

\footnotetext{
${ }^{11}$ Oneyda Alvarenga, chefe da Dicoteca Pública, subseção da Divisão de Expansão Cultural do Departamento de Cultura. Ocupou o cargo na Discoteca Pública de 1934 a 1968 tornou-se importante pela sua luta em organizar e preservar o acervo histórico da discoteca.
} 


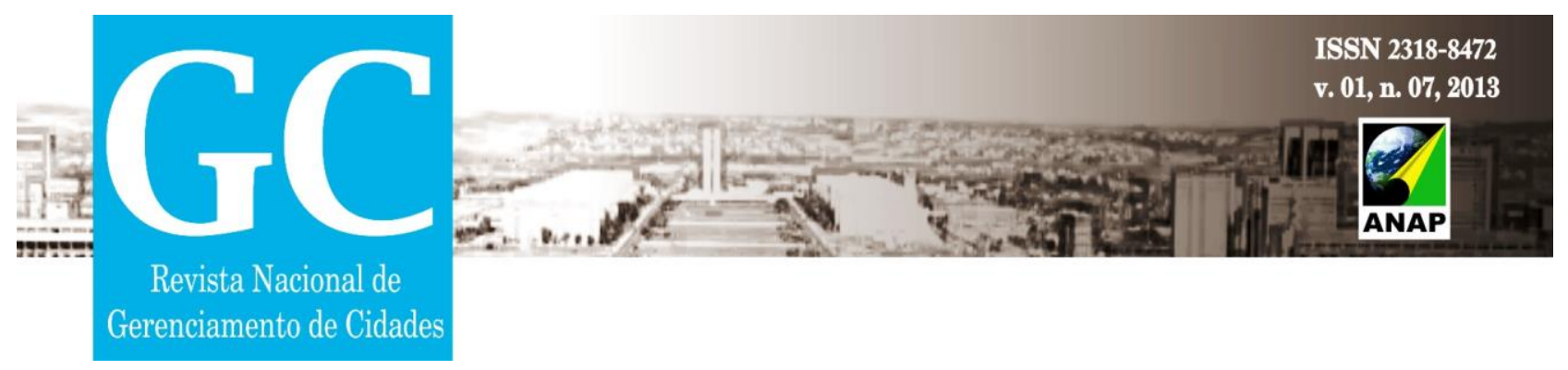

Em 1990 os registros sonoros foram finalmente digitalizados e José Saia Neto encarregou-se de decifrar as cadernetas utilizadas por seu pai, Luis Saia e os outros membros da missão. Em 2009 o material da pesquisa, anexo ao Acervo Histórico da Discoteca Oneyda Alvarenga foi reconhecido pelo Conselho Consultivo do IPHAN e foi aprovado um financiamento pela Caixa Econômica Federal com o objetivo de estudar e recuperar todo o material produzido na Missão de Pesquisa Folclórica realizada pelo Departamento de Cultura. Após ser estudado, catalogado e organizado, o material permanece como parte do Acervo Histórico da Discoteca Oneyda Alvarenga armazenado no Centro Cultural São Paulo na cidade de São Paulo. Em 2010 foi lançado um material com parte do conteúdo das cadernetas de campo da Missão Folclórica composto por um livro e um DVD onde estão reproduzidas cantigas gravadas, fotos e algumas das 3.500 páginas das cadernetas de campo.

\section{NA SÃo PAULO dE CRESCIMENTO FRENÉTICO, A IMPORTÂNCIA DE PRESERVAR AS RAÍZES DE UMA SOCIEDADE EM BUSCA DE SUA IDENTIDADE.}

Antes de compreender que o problema era puramente educacional, ainda fizeram com entusiasmo a Revolução de 32. Foi esta que, afinal, abriu os olhos de todos revelando a nossa carência terrível de homens. ${ }^{12}$

As propostas e realizações do Departamento de Cultura de São Paulo sob a gestão de Mário de Andrade é um assunto que proporciona inúmeros olhares. A preocupação da equipe do Departamento em trazer a proposta de preservação e a ideia de patrimônio era algo novo no período em que o Brasil, em especial São Paulo, ainda preocupava-se em se parecer cada vez mais com grandes cidades modernas da época. Arranha-céus, problemas com o trânsito nas ruas estreitas e tortuosas do centro velho, problemas

\footnotetext{
${ }^{12}$ MILLIET, SERGIO. Depoimento de Sérgio Milliet. In CAVALHEIRO, Edgar. O Testamento de Uma Geração: 26 figuras da intelectualidade brasileira prestam seu depoimento no inquérito promovido por Edgar Cavalheiro. Ed. Livraria do Globo, Porto Alegre, 1944 p. 237.
} 


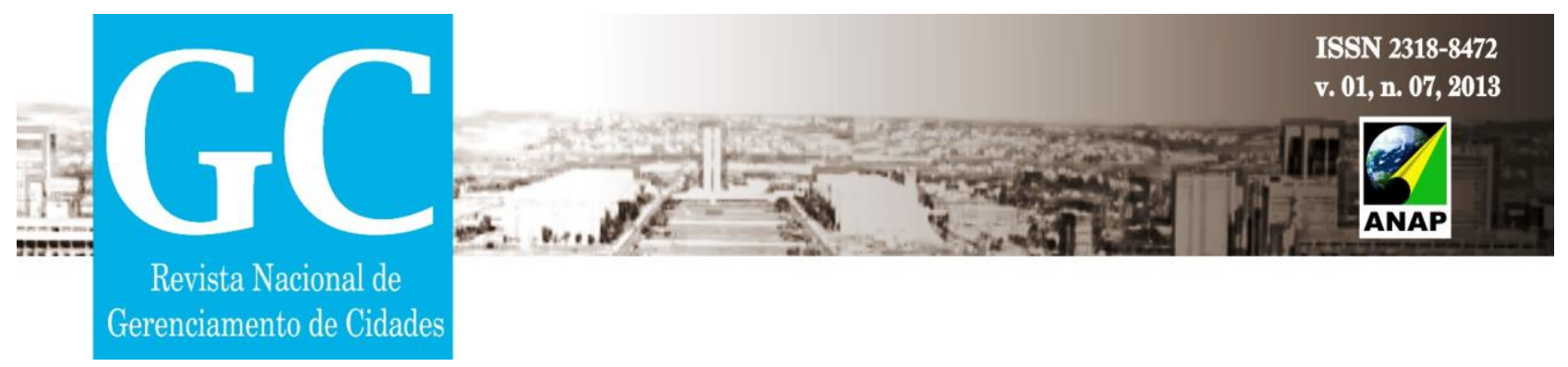

habitacionais e de infraestrutura na periferia já faziam parte do cenário urbano paulistano. O êxodo rural em função da crise do café desde o final da década de vinte e as grandes massas de imigrantes que chegavam ao Brasil, em especial em São Paulo, desde o início do século também evidenciavam um problema pelo qual a sociedade se mobilizou. $\mathrm{O}$ Brasil de tantas culturas precisava descobrir o que tinha de mais genuíno. Precisava descobrir dentre tantas referências culturais quais eram as suas raízes.

O Departamento de Cultura, que não era um projeto apenas de Mário de Andrade, mas de um grupo de intelectuais, técnicos, pesquisadores que se mobilizaram para tentar descobrir quais eram as raízes do Brasil. Para isso, foram pesquisar povos paulistas, interioranos, praianos, índios. Decidiram pesquisar zonas remotas do país, de acesso difícil para identificar e registrar manifestações genuínas do interior do norte e nordeste brasileiro. O plano era ambicioso, queria criar um Instituto de Cultura Brasileira, com base em pesquisas realizadas com as nascentes universidades brasileiras. Registraram o culto a Xangô (manifestação religiosa do Candomblé), o Catimbó, o desafio de viola e tantas outras danças, cantigas, festas e o cotidiano de comunidades remotas.

A enciclopédia ilustrada do folclore brasileiro, primeira etapa para a criação do Instituto Brasileiro de Cultura, não foi lançada, não passou sequer da fase de levantamento de dados e ficou praticamente esquecida por décadas. No entanto, a necessidade de preservar o patrimônio histórico cultural do Brasil, ideia trazida pelo Departamento de Cultura em São Paulo, se firmou com a criação do SPHAN, projeto pelo qual Lucio Costa se dedicou com afinco enquanto esteve à frente da secretaria. É evidente que muita coisa se perdeu, a ausência de leis regulamentares, fiscalização e mesmo falta de verbas deixou muitas memórias esquecidas pelo caminho. Preço da modernidade desejada e necessária. Embora tenha permanecido quase oculto durante quase sessenta anos, a recuperação do material trazido pela Missão de Pesquisas Folclóricas só foi possível graças aos avanços tecnológicos da tal modernidade, a mesma que muitas vezes justificam o desaparecimento de manifestações culturais antigas. Um desses casos em que a modernidade traz de volta coisas genuínas que pareciam perdidas, mas essa é outra discussão. O que importa, é que depois de tanto tempo, é 


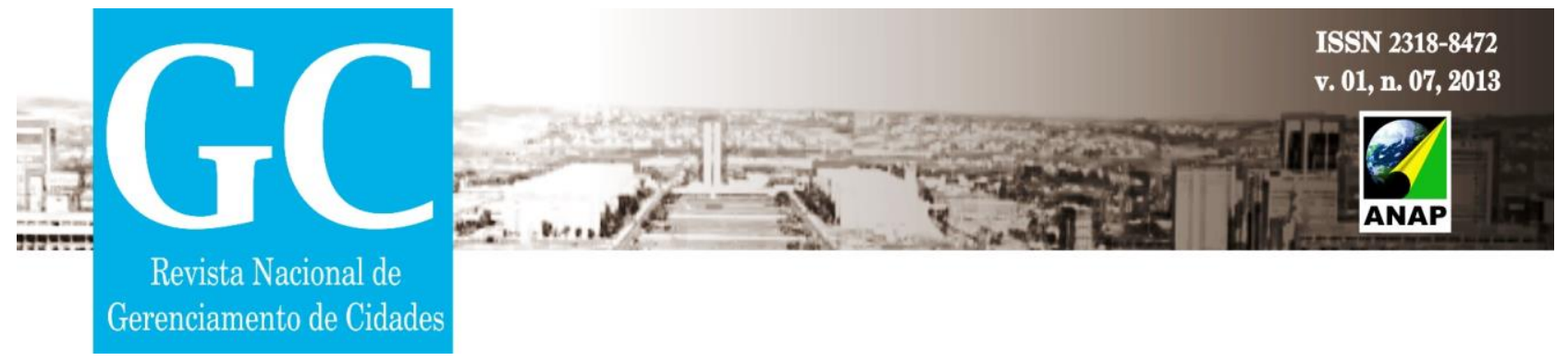

possível dizer a Mário de Andrade e todos os diretores e pesquisadores que trabalharam no Departamento de Cultura naqueles anos que os investimentos astronômicos na época para realizar a Missão de Pesquisas Folclórica valeram a pena e que de alguma forma, agora a enciclopédia ilustrada do folclore brasileiro existe.

\section{BIBLIOGRAFIA}

CALIL, Carlos Augusto. Mário da Cultura Andrade. In: CERQUEIRA, Vera Lucia Cardim de; Org. Cadernetas de Campo. Ed. Associação Amigos do Centro Cultural São Paulo, 2010, p. 3.

CAVALHEIRO, Edgar. O Testamento de uma Geração. 26 Figuras da intelectualidade brasileira prestam o seu depoimento no inquérito promovido por Edgar Cavalheiro. Ed. da Livraria Globo. 1944 p.237-243.

CERQUEIRA, Vera Lúcia Cardim de; Org. Missão de pesquisas folclóricas: cadernetas de campo. Associação Amigos do Centro Cultural São Paulo, 2010.

DUARTE, Paulo. Mário de Andrade por Ele Mesmo. HUCITEC, Secretaria Municipal de Cultura de São Paulo. São Paulo. 1985, p. 49 - 58.

DUARTE, Paulo. Sérgio Milliet. Boletim Bibliográfico da Biblioteca Mário de Andrade. v. 29, p. $19-25$, jul./set. 1972.

GONÇALVES, Lisbeth Rebollo. Sérgio Milliet, crítico de arte. Edusp e Ed. Perspectiva, São Paulo, 1992.

LOPEZ, Adriana; MOTA, Carlos Guilherme. História do Brasil. Uma interpretação. Ed. SENAC, São Paulo 2008.

MIRANDA, Nicanor. O Congresso Internacional de Folclore. Revista do Arquivo Municipal de São Paulo v. XLII, p. 79 - 96, dez. 1937. 


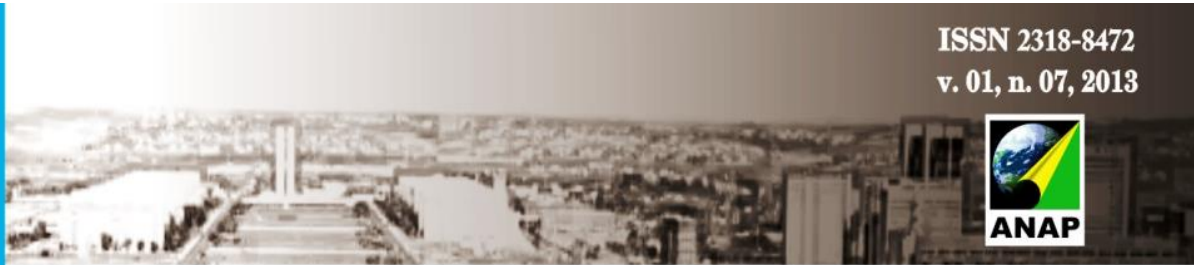

Revista Nacional de

Gerenciamento de Cidades

Regulamento do Departamento de Cultura. 30/05/1937 - Acervo do Arquivo Municipal de São Paulo.

SAIA NETO, José. Chegamos Bem. In: CERQUEIRA, Vera Lucia Cardim de; Org. Cadernetas de Campo. Ed. Associação Amigos do Centro Cultural São Paulo, 2010, p. 74.

TONI, Flávia Camargo. As cadernetas da missão de pesquisa folclórica. In: CERQUEIRA, Vera Lucia Cardim de; Org. Cadernetas de Campo. Ed. Associação Amigos do Centro Cultural São Paulo, 2010, p. 27.

\section{LISTA DE FIGURAS}

Figura 1, 2, 3 - Fonte: http://profclaytonribeiro.blogspot.com.br/2012/05/mario-de-andradee-missao-de-pesquisas.html

Figura 4 - Fonte: CERQUEIRA, Vera Lúcia Cardim de; Org. Missão de pesquisas folclóricas: cadernetas de campo. Associação Amigos do Centro Cultural São Paulo, 2010.

Figura 5 - Fonte: CERQUEIRA, Vera Lúcia Cardim de; Org. Missão de pesquisas folclóricas: cadernetas de campo. Associação Amigos do Centro Cultural São Paulo, 2010.

Figura 6 - Fonte: http://produto.mercadolivre.com.br/MLB-506390824-dvd-livro-missoesde-pesquisas-folcloricas-mario-d-andrade- JM 